\title{
O sonhar emancipatório e a educação
}

\author{
Eduardo Simonini Lopes*
}

\begin{abstract}
Resumo
O presente trabalho tem como principal objetivo problematizar o conceito de emancipação, especialmente sua apropriação pelo campo educacional. O referido conceito foi muito incorporado a discursos revolucionários - principalmente a partir do movimento iluminista no Século XVIII - para indicar a busca por uma vida mais livre, mais esclarecida e também mais feliz, trazendo, nesta perspectiva, orientações teleológicas que nutriram muitos sonhos político-ideológicoteológicos a promulgarem a possibilidade de se alcançar - pelas mais diferentes formas de lutas - instâncias de salvação coletiva e, ou bem-aventurança individual. A educação, quando significada como emancipatória, tendeu a fomentar propostas e práticas que muitas vezes se encontravam atreladas ao cultivo de ideais de progresso, desalienação ou empreendedorismo. Porém, acredita-se haver outras significações para o conceito de educação emancipatória, principalmente quando se aborda a emancipação não pela perspectiva do progresso ou da evolução, mas por uma orientação que se apóia em políticas de invenção, promotoras de crises, rupturas e movimentos que possam fazer nascer maneiras de pensar-agir não mapeadas e passíveis de criação de novas sensibilidades.
\end{abstract}

Palavras-chave: Emancipação. Educação. Invenção.

\section{The emancipatory dreaming and the education}

\begin{abstract}
The main aim of the present work is to problematize the concept of emancipation, specially its appropriation by the educational field. The referred concept was often incorporated to revolutionary speeches - mainly after the illuminist movement in the XVIII century - to indicate the search for a life which would be more free, more clear and also happier, bringing, in this perspective, teleological orientations which entertained many political-ideological-theological dreams to enact the possibility of reaching - through the several different forms of fight - instances of collective salvation and/or individual blessedness. The education, when meant as emancipatory, tended to promote proposals and practices which were often found binded to the cultivation of progress, inalienation or entrepreneurship ideals.
\end{abstract}

\footnotetext{
* Professor da Universidade Federal de Viçosa (MG), Centro de Ciências Humanas, Letras e Artes, Departamento de Educação. Viçosa, Minas Gerais, Braisil.
} 


\section{Eduardo S. Lopes}

Nevertheless, other significations for the concept of emancipatory education are believed to exist, mainly when one approaches the emancipation not by the perspective of progress or evolution, but by an orientation which is based on intervention policies, promoters of crisis, breaks and movements which can give birth to new ways of thinking-acting not yet mapped and passive creation new sensibilities.

Keywords: Emancipation. Education. Invention.

\section{O sonhar emancipatório e a educação}

Conceitos não são entidades autônomas; não possuem luz própria ou independência existencial e, de acordo com Deleuze e Guattari (1996, p. 13), eles "não nos esperam inteiramente feitos, como corpos celestes. Não há céu para os conceitos. Eles devem ser inventados, fabricados ou antes criados, e não seriam nada sem a assinatura daqueles que os criam". Não nascendo do vazio, os conceitos necessitam de um contexto e de um problema para emergirem e serem preenchidos de sentido. Assim, um conceito é criado na tentativa de "tamponar" uma ausência de significação e de coordenadas diante das desestabilizações de mundo, forçando a pensar e a construir pontes explicativas entre o que era já conhecido e o que ainda está indefinido. O conceito de "paz", por exemplo, não existia até o momento em que ocorreram conflitos que justificaram a criação do conceito de "guerra" e, por conseguinte, a invenção da possibilidade de um estado (ainda que abstrato) ao qual se chamou de "paz".

Desta maneira, o ser humano se estabeleceu como criador de conceitos; muitos destes já possuindo, em sua nascente, uma proposta de beleza e frescor cristalinos a partir dos quais se sonhou materializar sentidos universais que não necessitariam de maiores esclarecimentos para serem entendidos. Trariam consigo um ideal de plenitude supostamente compreendidos por todos os povos e em todas as épocas, tornando-se baluartes para a humanidade. Foi dessa maneira que a poetisa Cecília Meireles parece ter compreendido o conceito de liberdade quando escreveu uma de suas mais famosas quadras:

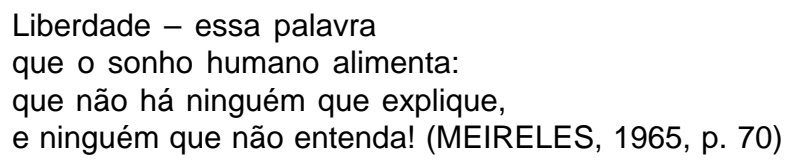

À distância, tais conceitos "sublimes" (e à "liberdade" se somam "paz", "igualdade", "democracia", dentre outros) parecem unificados, harmônicos, funcionando como indicativos para terras há muito prometidas e aparentemente alcançadas apenas por seres eleitos. Quando, porém, aproximamo-nos dos mesmos, eles tendem a também se mostrar arredios, contraditórios, indomados. Dentro desse panorama, a "liberdade" é uma instância mágica que movimenta corações, mobiliza motivações, aduba sonhos e fortalece esperanças; todavia, 
a busca pela substancialização da liberdade também nutre conflitos, crueldades e assassínios. Se sonhos libertários acalentam a imaginação humana, o conceito de liberdade possui tantos sentidos diferentes e configurações contraditórias que os sujeitos chegam mesmo a se agredir em ferozes discordâncias e violentos crimes na tentativa de possuí-la. Entre as várias significações erigidas, Bauman nos diz que liberdade:

significa literalmente libertar-se de algum tipo de grilhão que obstrui ou impede os movimentos; começar sentirse livre para se mover ou agir. "Sentir-se livre" significa não experimentar dificuldade, obstáculo, resistência ou qualquer impedimento aos movimentos pretendidos ou concebíveis. [...] sentimo-nos livres na medida em que a imaginação não vai mais longe que nossos desejos e que nem uma nem os outros ultrapassam nossa capacidade de agir. (BAUMAN, 2001, p. 23-24)

Apoiado nas considerações de Bauman, sustento, então, o argumento de que um estado libertário não é necessariamente um "estado de graça" ou uma dimensão restrita apenas à conquista do direito de ir e vir e, ou dizer/fazer o que se quer, mas se configura também no estabelecimento de uma zona de confronto na qual uma liberdade se constituiria enquanto tal a partir da legitimação de uma potência, do domínio de um território, de uma vontade que se hegemoniza - mas não necessariamente suprime - a outras. "Afinal, a liberdade é a capacidade de fazer com que as coisas sejam realizadas do modo como queremos, sem que ninguém seja capaz de resistir ao resultado, e muito menos desfazêIo" (BAUMAN, 2003, p. 26).

Reside, nesse ponto, um elemento conflitivo inerente às práticas libertárias porque cada indivíduo ou grupo, buscando produzir seu livre movimento, considerará muitas vezes a liberdade alheia como um incômodo e, ou uma oposição. Por isso, temos que os sonhos de liberdade são sempre marcados pelo confronto contra algo ou alguém a superar, a fim de fazer valer o livre trânsito das vontades contidas ou declaradas. E é esse anseio por liberdade, pela materialização dos desejos e o abandono dos grilhões que aprisionam, que se definiu, classicamente, como sendo emancipação.

\section{Emancipações}

Emancipação é um conceito complexo que foi abraçado como um norteador da modernidade, principalmente a partir da proposta iluminista (Século XVIII) de trazer mais clareza à verdade do mundo e erradicar as "visões erradas" que as pessoas nutriam sobre a natureza e a vida. Emancipar a sociedade significaria libertar os sujeitos dos preconceitos a fim de que pudessem "enxergar melhor" a "realidade". Porém, a emancipação, no momento em que se tornou um conceito absorvido por variados contextos sociopolíticos, ganhou orientações diferenciadas que vivificaram outros sentidos para além dos iluministas. 


\section{Eduardo S. Lopes}

O sociólogo argentino Ernesto Laclau ofereceu expressiva contribuição crítica a essa temática, ao ponderar sobre as diferentes dimensões desempenhadas pelo conceito de emancipação e como as mesmas se complementavam e, ou se excluíam no entendimento de tal processo. Ele procurou destrinchar algumas variações de sentido herdadas tanto das perspectivas emancipatórias iluministas quanto religiosas: ambas de cunho transcendente e teleológico. Para o referido autor, uma das compreensões do que vem a ser um movimento emancipatório tem se consistido na crença de que existe uma emancipação real e que, para se chegar a esta, há a necessidade de se lutar contra um "outro" que obstrui a possibilidade de a emancipação se realizar de forma plena. Tal entendimento de ação emancipatória já suporia a preexistência de uma identidade a ser emancipada; o que igualmente subentende a preexistência de um mundo-verdadeiro a se alcançar através da superação das alienações promovidas por um "outro" opositor. Claro que tal "outro" não necessariamente teria que ser uma pessoa física, podendo ser também uma ideologia, um sistema político, uma orientação religiosa..., enfim, qualquer expressão a ser superada a fim de que se conquiste um sonho de liberdade. Nesse caso, "não há emancipação sem opressão, e não há opressão sem a presença de algo que tem impedido seu livre desenvolvimento pelas forças opressoras. Emancipação não é, nesse sentido, um ato de criação, mas a libertação de algo que precede a ação libertadora" (LACLAU, 2007, p. 1 - tradução minha).

Laclau também apresentou o conceito de emancipação como igualmente atrelado a uma dimensão de transparência, uma vez que existiria a crença na possibilidade de que a alienação pudesse ser erradicada por meio de uma conscientização emancipatória, a qual ofereceria acesso ao vislumbre de uma essência humana comum e límpida, sem a interferência das águas turvas trazidas pelas "falsas" ideologias, "falsas" interpretações e lideranças enganadoras. Seguindo por esse caminho pavimentado pela crença na existência de um mundoverdade a ser alcançado, a emancipação igualmente estaria ligada à perspectiva de que um Deus ou um grande líder visionário indicaria o caminho para a realização da felicidade de um grupo, apontando para o local já predefinido de libertação. Nesse sentido, toda autoridade estaria nas mãos de alguns poucos timoneiros que, conhecendo as mazelas do trajeto, conduziriam a tribulação por entre as tormentas da viagem, protegendo-a de naufragar perante as tempestades.

Dissecando as diferentes dimensões do conceito de emancipação em sua perspectiva transcendente, Laclau realizou uma crítica a toda abordagem que traz consigo promessas libertário-salvacionistas encarnadas em líderes e, ou em ideais a serem substancializados. Não se furta, portanto, de alertar que qualquer tentativa de produzir um movimento emancipatório que aspire a sua plena realização; que anseie por atingir um tipo de ideal sonhado; torna-se uma porta aberta a totalitarismos, já que os opositores teriam que ser continuamente vigiados e, ou silenciados para que o sonho de liberdade ideal não fosse maculado. E, como disse Marx (2002, p. 56), "uma esfera social particular terá 
de olhar-se como o crime notório de toda a sociedade, a fim de que a emancipação de semelhante esfera surja como uma emancipação geral. Para que uma classe seja libertadora par excellence, é necessário que outra classe se revele abertamente como opressora". Assim, um grupo que conquista sua emancipação potencialmente constrói, de maneira concomitante, suas zonas de opressão e silenciamento no intento de manter seu grau de domínio e legitimidade sobre a nova condição conquistada.

O que determinado grupo consideraria uma abertura emancipatória pode igualmente se tornar uma severa constrição para outro grupo; principalmente se este último for classificado como um crime notório de toda a sociedade. Portanto, temos que processos que se anunciam como emancipatórios, libertários e salvadores podem igualmente produzir seus campos de aprisionamento e opressão a qualquer produção de vida que não corresponda aos direcionamentos desejados pelo grupo que se emancipa. Aqueles, na tentativa de se contrapor às polifonias, propõem-se muitas vezes a erigir e, ou resgatar sonhos de uma vida considerada como um mundo mais feliz, esperançosos de que esses mundos oniricamente edificados venham a ser um plano diretor para toda a humanidade.

\section{Emancipação e invenção}

Novos horizontes...! Se não for isso, o que será?! Quem constrói a ponte não conhece o lado de lá. (HAWAll, 2000)

Boaventura Santos não estava ausente a esse paradoxo que as propostas emancipatórias carregam consigo; paradoxo este que consiste na possibilidade de um ação emancipatória ser portadora tanto de abertura de caminhos quanto de cerceamento de possibilidades. Pensando o movimento emancipatório enquanto um deslocamento contextual, circunscrito a um tempo e a um espaço de um grupo ou comunidade, Santos ponderou a respeito das ambivalências e riscos de tal movimento ao levantar as seguintes questões:

O que é, afinal, emancipação social? É possível ou legítimo defini-la abstratamente? Se é verdade que não há uma, mas várias globalizações, não será igualmente verdade que não há uma, mas várias formas de emancipação social? Tal como a ciência, não será a emancipação social de natureza multicultural, definível e validável apenas em certos contextos, lugares e circunstâncias, uma vez que o que é emancipação social para um grupo social ou em um dado momento histórico pode ser considerado regulação ou mesmo opressão social para outro grupo social ou em um momento histórico seguinte ou anterior? Todas as lutas contra a opressão quaisquer que sejam seus meios e objetivos são lutas pela emancipação social? É possível emancipação social sem emancipação individual? Emancipação social para 


\begin{abstract}
quem e para quê, contra quem e contra quê? Quem são os agentes da emancipação social? Há algum agente privilegiado? As forças sociais e institucionais hegemônicas, como, por exemplo, o Estado, podem ser cúmplices ou colaboradores ativos de ações de emancipação social? [...] Corremos o risco de promover a opressão social usando a linguagem da emancipação social? (SANTOS, 2002, p. 23-24)
\end{abstract}

Os questionamentos propostos por Boaventura Santos nos desafiam a um contínuo policiamento em torno das motivações que nutrem os projetos de mundo e as práticas de intervenção nos universos sociais dentro dos quais nos inserimos. A orientação de Santos nos convida a pensar que o agir emancipatório não existe "em si", uma vez que este é sempre relacional e, por isso mesmo, dependente das lutas circunstanciais e interesses dos envolvidos. Não necessariamente está atrelado a um projeto coeso, teleológico e estático, podendo consistir em uma política articulatória de forças e interesses na instauração de um mundo; de uma realidade a potencializar oportunidades e ou obstacularizar perspectivas. É esse tipo de pensamento que faz com que Santos busque ampliar o conceito de emancipação para além de seu aspecto transcendente, inserindo-o nas lutas circunstanciais e cotidianas, principalmente quando argumenta que "[...] a transformação emancipatória não tem teleologia nem garantia, [...] a emancipação não é mais que um conjunto de lutas processuais, sem fim definido" (SANTOS, 2006, p. 277). Mas, mesmo que não possuam uma finalidade específica, as consequências das ações coletivas dessas lutas produzem regulação de mundos e produção de verdades orientadoras de maneiras como os sujeitos observarão a si próprios e os processos de vida nos quais se inserem.

O conceito de emancipação, como indicado por Santos, deixa, então, de significar o alcançar a segurança de um local sonhado para vir a ser uma abertura ao risco, à experimentação e à novidade. Tal posicionamento situa a emancipação não mais como um projeto iluminista ou progressista - já que a própria noção de progresso subentende um conjunto linear de fases e níveis a galgar, tendo como referência algum modelo de perfeição a se atingir -, mas como um processo inventivo que pode vir a ser abortado a qualquer momento pelo próprio nível de insegurança e a ansiedade que nascem do desamparo e desnorteamento a que estão condenados aqueles que criam em meio ao que ainda não existe.

Felix Guattari realizou, a exemplo de Boaventura Santos, problematizações a respeito dos processos revolucionários enquanto instâncias efetivamente emancipatórias. Guattari insistiu que a luta por maiores espaços de liberdade se torna uma prática necessária à vida não apenas da sociedade como um todo, mas do indivíduo em sua singularidade vivencial: na relação com seus parceiros, amigos, vizinhos, familiares, colegas de trabalho. Porém, segundo ele, uma proposta de ação revolucionária: 
[...] é algo da natureza de um processo, de uma mudança que faz com que não se volte mais para o mesmo ponto. [...] Então, por definição, uma revolução não pode ser programada, pois aquilo que se programa é sempre o déjà-là. As revoluções, assim como a História, sempre trazem surpresas. Por natureza elas são sempre imprevisíveis. Isso em nada impede que se trabalhe pelas revoluções, desde que se entenda esse "trabalhar pela revolução" como sendo trabalhar pelo imprevisível. (GUATTARI; ROLNIK, 2005, p. 212-213, grifo meu)

Se os processos emancipatórios, enquanto aberturas à invenção, margeiam perspectivas imprevistas e apostas temerosas, temos, por sua vez, que a busca por segurança e controle de um processo revolucionário já carregaria consigo os germes de ditaduras estéticas e políticas para a vida. As dinâmicas emancipatórias, na leitura feita por Guattari, não emergem necessariamente de movimentos planejados e previamente organizados para tal fim. Quando ocorrem, o fazem muitas vezes a partir do encontro entre territórios sociais que, articulando interesses e afinidades, podem promover mobilizações coletivas que surgem e desaparecem sem necessariamente terem continuidade ou desdobramentos aparentes.

O sociólogo Lúcio Kowarick igualmente defende que dinâmicas emancipatórias não se coadunam com a perspectiva da salvação, redenção ou progresso, chegando mesmo a considerar que é necessário desmontar a falácia de que os movimentos sociais - ocorrendo nas escolas, nas empresas, nas fábricas, nas famílias,...-, sejam homogêneos e redentores, possuindo, a priori, metas históricas a serem atingidas. Ao contrário:

[...] é a partir de uma análise por dentro dos movimentos que se deve entender seus fluxos e refluxos, sua capacidade de invenção e articulação com outras forças sociais, em face de acontecimentos que se desenrolam no caminhar da luta, cujos resultados não estão, de antemão, estipulados por categorias analíticas que amarram os diversos agentes a uma trama previamente estabelecida. [...] É esse percurso - marcado por diversidades plenas de desvios, caracterizado pela constante recomposição de divisões e alianças - que cabe reconstruir, recompondo as trilhas cotidianas das lutas. (KOWARICK, 2000, p. 72-73)

As articulações de Kowarick se orientam na direção de considerar que as práticas emancipatórias não se encontram enquadradas em projetos ideais sustentados sobre realidades pré-configuradas, mas sim em movimentos incertos que solicitam a inventividade de novos arranjos de sentido. Ele insiste que, se os encontros sociais são imprevistos e tantas vezes desarticulados, isso não impede que tais movimentos - forjados nas relações de vizinhança, em 


\section{Eduardo S. Lopes}

meio aos atrasos dos transportes, no enfrentamento a doenças, nas "insignificâncias" do dia-a-dia - venham a produzir focos de confluência de interesses que, perante "à diversidade de trajetórias [...], acabam criando formas de solidariedade mais amplas e coletivas, quando então transparece um momento de fusão dos conflitos e reivindicações" (KOWARICK, 2000, p. 77), inaugurando núcleos de colaboração e vitalidade, mesmo que provisórios. O que ratifica as argumentações de Inês Barbosa de Oliveira, quando esta sustenta que, ao se considerar a emancipação social como:

[...] o conjunto das lutas processuais desenvolvidas nos diversos contextos e circunstâncias sociais, entenderemos que tais contextos e circunstâncias definem as prioridades dos momentos específicos, não sendo, portanto, passíveis de generalizações estruturalistas nem de hierarquização estrutural, tampouco de leituras que os analisem separadamente. (OLIVEIRA, 2003, p. 28)

Quando, pois, propomo-nos a problematizar o conceito de emancipação, deparamo-nos com a concepção de que o mesmo se inscreve em duas perspectivas principais. Na primeira, encontramos uma orientação transcendente, na qual "se emancipar" faz referência a seguir o caminho de uma verdade maior para o engrandecimento da nação, para a felicidade, para a evolução espiritual, para a maturidade ou a plenitude moral. A segunda perspectiva situa a emancipação dentro de dinâmicas contextualmente circunscritas e não a estados a serem atingidos por uma ascensão qualitativa. A emancipação estaria, então, muito mais ligada à multiplicação das conexões articulatórias - mobilizando a amplificação provisória de um campo de possíveis - do que a um projeto que pré-configuraria um ideal a habitar. Nesta segunda perspectiva, os processos emancipatórios valem mais pelos movimentos que mobilizam no corpo social do que propriamente pelo fomento de verdades triunfantes.

Ambas as perspectivas do conceito de emancipação não são excludentes e podem coahabitar, não sem conflitos ou contradições, um mesmo espaço social ou processo grupal. Porém, a priorização de uma das perspectivas produz consequências políticas diferenciadas, propostas educacionais distintas, assim como modos diversos de se pensar e empreender intervenções sociais.

\section{Educações emancipatórias}

Quando, pois, trazemos a discussão sobre emancipação social para o campo dos processos de aprendizagem, observamos o quão intimamente o conceito de educação se encontra entrelaçado ao de emancipação. Essa cumplicidade conceitual se comprometeu mais especificamente com a perspectiva transcendente e salvacionista do movimento emancipatório, acreditando na possibilidade de $o$ ato educativo - em especial aquele realizado dentro das escolas - propiciar o alcance a um mundo mais digno e verdadeiro por meio do extermí- 
nio das desigualdades, da ignorância e da alienação. O próprio conceito de educação já nasce, etimologicamente, envolvido na ambição iluminista de dar à luz um suposto potencial latente no ser humano, uma vez que "educare, no latim, era um verbo que tinha o sentido de criar (uma criança), nutrir, fazer crescer. Etimologicamente, poderíamos afirmar que educação, do verbo educar, significa trazer à luz a idéia" (MARTINS, 2005, p. 33).

Enquanto um "fazer crescer" é materializar potências, educar é, intrinsecamente, um ato emancipatório. Consciente de que tal afirmação possa ser polêmica, acredito, todavia, que por mais restrito e reacionário que seja um processo educacional, ele ainda oferece ferramentas que potencializam produções de sentido e invenções de realidade: independente do julgamento de valor que se faça em torno de tais produções de realidade. Por esse motivo, entendo que os processos educacionais produzem maneiras de enxergar, sentir e experienciar o viver que, propiciando modos de pensar, definem os terrenos epistemológicos nos quais os diferentes grupos transitarão. Se tais construções de pensamento se conectam a conceitos como "progresso", "liberdade" ou "alienação" o fazem a partir dos valores e significações particulares do que venham a ser tais conceitos para um grupo determinado. É necessário, pois, terse a consciência de que estamos sempre correndo o risco de fazer julgamentos de valor quando propomos que a educação liberta, salva ou aliena, já que esses conceitos estariam envolvidos nas construções políticas, cognitivas, familiares, midiáticas, mercadológicas..., que nos subjetivam e, consequentemente, nos modos como acreditamos que deva ser o mundo e a vida. Os conceitos de educação e de emancipação respondem, portanto, a contextos complexos, modelando-se às necessidades e aos valores políticos e historicamente construídos pelos mais diferentes atores sociais.

Mas se toda educação, de certa forma, emancipa, uma vez que promove o parto de universos, temos, porém, que nem toda ação educativa produz coeficientes de flexibilidade que potencializarão a multiplicação das expressões, pensamentos e sensações. Sendo a dinâmica educacional interconstituinte à produção de mundos - a modos de compor corpos, temporalidades, espaços, histórias e pensamentos - não posso dizer que, neste processo, todos os corpos, tempos e pensares terão direito à ampla existência e à pluralidade de expressões. E se nem todas as expressões e tendências serão possíveis, pergunto-me: que modelos de emancipação se legitimam no cotidiano das práticas escolares? Em que direção se montam as produções de mundo dentro das dinâmicas educacionais: potencializam encontros? Abortam perspectivas? Dialogam com a incerteza e ou estabelecem "mundos prontos" onde as diferenças têm que buscar seus encaixes para não serem expelidas?

O pedagogo Jorge Larrosa fez coro a tais questões quando se dedicou a problematizar a respeito do quanto os processos educacionais - ao conclamar o progresso, o empreendedorismo e a emancipação como objetivos a se alcançar - correm o risco de empobrecer a experiência da aprendizagem e 


\section{Eduardo S. Lopes}

da invenção no momento em que seduzem docentes e discentes a ambicionar modelos de mundos já predefinidos e que, talvez por sua promessa de estabilidade, tendam a ser considerados mais "certos" e "seguros" para o bem-estar social. Larrosa construiu, assim, críticas a propostas emancipatórias que pretendem promover "uma determinada idéia de vida humana, da convivência humana ou do progresso humano, que a educação, a partir da infância, deveria tratar de realizar" (LARROSA, 2003, p. 188). Tais propostas carregariam consigo a expectativa de que a escola, direcionando-se às necessidades imediatas da cultura, da economia mundial, de algum tipo de projeção futurista, teria que promover uma formação "sólida", competitiva, planejada e adaptada a um mundo "pós-moderno", entendido pelo prisma da fluidez empresarial, da mutabilidade do mercado, das expectativas por trabalhadores desenraizados e sempre preparados para mudanças. Nessa perspectiva, a educação seria, em suma, a obra de um pensamento calculador e de uma ação técnica "[...] em que o resultado deve ser produzido segundo o que foi previsto antes de iniciar" (LARROSA, 2003, p. 193).

Após denunciar o risco de empobrecimento da experiência do aprender, quando o processo educativo é submergido em expectativas emancipatórias que apresentam como carro-chefe os conceitos de progresso e competitividade, Larrosa traz, em suas argumentações, uma outra significação para os processos emancipatórios em educação: o entendimento de que estes também podem fomentar aberturas à experimentação inventiva. No momento em que se propõe a entender cada ser humano como uma entidade que, ao nascer, inaugura uma novidade no mundo, não sendo apenas um vasilhame a ser preenchido por informações, a educação passa a ser interpelada não como uma fôrma adaptativa, mas sim como uma ferramenta potencializadora de virtualidades que animam indivíduos e grupos. É uma educação que catalisa o surgimento de rupturas, bifurcações, incertezas e a construção de outras possibilidades de universos não redutíveis às lógicas hegemônicas de determinada época. A essa educação, marcada pelo questionamento de verdades cristalizadas e legitimadora da ousadia de um aprender experimental, localizamos como partidária de uma política da invenção. Não uma política inventiva gestada em meio a destinos e utilidades teleologicamente planejados, mas sim mobilizada por uma permanente tensão "[...] entre a ação e a problematização. Trata-se de seguir sempre um caminho de vaivém, inventar problemas e produzir soluções, sem abandonar a experimentação. [...] É o exercício de uma coragem prudente" (KASTRUP, 1999, p. 204). Nesses termos, ao falar em educação emancipatória, refiro-me àquela comprometida com o fomento de aberturas e explorações inventivas que não se caracterizam como exceções às regras estabelecidas, mas sim como excessos, transbordamentos que forçam novos modos de pensar; outras possibilidades no agir.

A emancipação é apresentada, então, não como um destino fixo, mas como um movimento de intensidade: 1) quando se coloca em movimento uma potência de ver, de agir, de sentir; 2) quando se criam condições para o surgimento 
de possibilidades expressivas inexistentes até então, tendo-se a consciência de que o fomento de aberturas de universo em nada está comprometido com garantias de salvação ou de "dias melhores". Dentro desse contexto, Guattari (1987) alerta que lutar por políticas inventivas e pela polivocidade da expressão na educação não significa que se tenha por projeto a fabricação de marginais, delinquentes ou entidades revoltosas, mas sim a possibilidade de se oferecer condições para que os sujeitos e engendramentos grupais, ao resolverem assumir os papéis que um sistema de significações hegemônicas lhes apresenta, não façam dos mesmos uma segunda pele a ponto de não mais poderem se desfazer destes, perdendo, assim, a potência de (re)inventar expressões e de oferecer a si mesmos, e às relações nas quais se comprometem, outros coeficientes de flexibilidade e oxigenação.

Seguindo as considerações de Guattari, acredito que não se trata, portanto, de se buscar opor um tipo de emancipação a outro, tomando-os como essências. Enquanto movimento de produção de mundos, propostas emancipatórias em educação se enamoram com um certo grau de experimentação e invenção, assim também com o desenho de horizontes "ideais" a se atingir. O que coloco em questão não é qual perspectiva se apresenta como mais verdadeira, mas sim o quanto, no movimento de se desenhar tais experimentações e horizontes "libertários", serão aceitas também formas inusitadas de rabiscos..., linhas de fuga que indicam outras perspectivas possíveis...; ou se, ao contrário, só serão autorizadas viseiras que limitem o horizonte a um ponto marcado a alcançar, estabelecendo a ditadura da Verdade; ditadura esta muitas vezes maquiada por discursos que se passam por libertários.

Sem pretender, portanto, fomentar dicotomias, anseio por fugir da armadilha que é a de eleger uma perspectiva emancipatória como sendo melhor, mais eficiente ou mais verdadeira. Neste sentido, prefiro me aliar ao prudente conselho de Tomaz Tadeu da Silva quando nos ensina que "nada, nem ninguém, é contra-hegemônico ou revolucionário ou emancipatório para sempre e de uma vez por todas. O contra-hegemônico, o emancipatório, o revolucionário não são essências" (SILVA, 2002, p. 13).

Todavia, seja comprometida com a inventividade ou com uma perspectiva mais formativa, a educação perde seu viés problematizador no momento em que se instala no pomo da Verdade e não permite que se façam outros questionamentos e arranjos que desafiem estabilidades conquistadas. Os movimentos educativos perdem, assim, sua flexibilidade articulatória quando um modelo considerado progressista vem a aniquilar outros entendimentos sobre o que vem a ser progresso; ou quando uma proposta inventada subalterniza outros tantos processos inventivos.

É baseado nisso que acredito que a condição primordial para uma proposta emancipatória não se cristalizar em um projeto totalitário diz respeito à sua própria mortalidade; à sua própria aniquilação. É necessário ousar morrer, 
ousar abandonar antigas estratégias (que muitas vezes tão bem funcionavam) a fim de esboçar outras possíveis; fazer nascer novos ritmos que não se aliem exclusivamente à repetição do já estabilizado. É um processo que em muito lembra a imagem poética criada pelo escritor Hermann Hesse quando este nos conta que "a ave sai do ovo. O ovo é o mundo. Quem quiser nascer tem que destruir um mundo" (HESSE, 1997, p. 114). E a educação, em sua dinâmica emancipatória, comunga com movimentos que promovem a destruição de mundos, assim também com o fomento de gestações e partos que, rompendo continuidades, oportunizam novos começos que podem tanto vir a repetir velhos caminhos quanto inaugurar diferentes perspectivas.

Acredito, assim, que emancipar não seja simplesmente um "libertarse" de algo ou alguém. Emancipação envolve comprometimento com políticas marcadas por transformações, por rupturas, por dinâmicas de nascer-morrerrenascer-inventar as quais acompanham cada ser humano, cada ato social, cada proposta educativa a vivificar diferentes arranjos de sentido em meio ao cultivo de provisórias "verdades" e à multiplicação da potência de sonhar.

O sonho nada tem a ver com a ilusão. A concretude da vida, sobretudo de vidas alegres, começa pela potência onírica. "[...] O mundo que os homens chamam real, não existe! A realidade não é algo acabado cujo peso devemos carregar. Mundo real? É preciso que o inventemos" (FUGANTI, 1991, p. 69).

\section{Referências}

BAUMAN, Z. Modernidade líquida. Rio de Janeiro: Jorge Zahar, 2001.

. Comunidade. Rio de Janeiro: Jorge Zahar, 2003.

DELEUZE, G. Two regimes of madness. New York: Semiotext(e), 2006.

DELEUZE, G.; GUATTARI, F. O que é a filosofia? Rio de Janeiro: Editora 34, 1996.

FUGANTI, L. A. Saúde, desejo e pensamento. In: LANCETTI, A. (Org.). Saudeloucura. São Paulo: Hucitec, 1991.

GUATTARI, F. Revolução molecular. São Paulo: Brasiliense. 3. ed., 1987.

GUATTARI, F.; ROLNIK, S. Micropolítica: cartografias do desejo. Petrópolis: 7. ed. Vozes, 2005.

HAWAII, Engenheiros. Novos Horizontes. Humberto Gessinger [Compositor]. In: 10.000 Destinos. Universal, 2000. 1 CD. Faixa 18. Remasterizado em digital.

HESSE, H. Demian. 29. ed. Rio de Janeiro: Record, 1997.

KASTRUP, V. A invenção de si e do mundo. Campinas: Papirus, 1999.

KOWARICK, L. Escritos urbanos. São Paulo: Ed. 34, 2000. 
LACLAU, E. Emancipation(s). London/New York: Verso, 2007.

LARROSA, J. Pedagogia profana. Belo Horizonte: Autêntica, 2003.

MARTINS, E. S. A etimologia de alguns vocábulos referentes à educação. Revista Olhares e Trilhas. Uberlândia, ano VI, n. 6, p. 31-36, 2005.

MARX, K. Manuscritos econômicos-filosóficos. São Paulo: Martin Claret, 2002.

MEIRELES, C. Romanceiro da inconfidência. Rio de Janeiro: Letras e Artes, 1965.

OLIVEIRA, I. B. de. Currículos praticados. Rio de Janeiro: DP\&A, 2003.

SANTOS, B. S. (Org.). Democratizar a democracia. Rio de Janeiro: Civilização Brasileira, 2002.

Pela mão de Alice. São Paulo: Cortez, 2006.

SILVA, T. T. da. Mapeando a [complexa] produção teórica educacional. Currículo sem fronteiras, v. 2, n. 1, p. 5-14, jan./jun. 2002.

\section{Correspondência}

Eduardo Simonini Lopes - Avenida PH Rolfs, s/n, CEP 36570-000, Viçosa (MG).

E-mail: simonini1@yahoo.com.br

Recebido em 15 de outubro de 2009

Aprovado em 01 de dezembro de 2009 
